\title{
Rare Mutations of Peroxisome Proliferator-Activated Receptor Gamma: Frequencies and Relationship with Insulin Resistance and Diabetes Risk in the Mixed Ancestry Population from South Africa
}

\author{
Z. Vergotine, ${ }^{1,2}$ A. P. Kengne, ${ }^{3}$ R. T. Erasmus, ${ }^{2}$ Y. Y. Yako, ${ }^{1}$ and T. E. Matsha ${ }^{1}$ \\ ${ }^{1}$ Biomedical Sciences, Faculty of Health and Wellness Sciences, Cape Peninsula University of Technology, P.O. Box 1906, \\ Bellville, Cape Town 7530, South Africa \\ ${ }^{2}$ Division of Chemical Pathology, Stellenbosch University, Cape Town 7505, South Africa \\ ${ }^{3}$ Non-Communicable Diseases Research Unit, South African Medical Research Council and University of Cape Town, \\ Cape Town 7505, South Africa
}

Correspondence should be addressed to T. E. Matsha; matshat@cput.ac.za

Received 19 May 2014; Accepted 16 July 2014; Published 14 August 2014

Academic Editor: Hyun C. Lee

Copyright (C) 2014 Z. Vergotine et al. This is an open access article distributed under the Creative Commons Attribution License, which permits unrestricted use, distribution, and reproduction in any medium, provided the original work is properly cited.

Background. Genetic variants in the nuclear transcription receptor, PPARG, are associated with cardiometabolic traits, but reports remain conflicting. We determined the frequency and the clinical relevance of PPARG SNPs in an African mixed ancestry population. Methods. In a cross-sectional study, 820 participants were genotyped for rs1800571, rs72551362, rs72551363, rs72551364, and rs3856806, using allele-specific TaqMan technology. The homeostatic model assessment of insulin (HOMA-IR), $\beta$-cells function (HOMA-B\%), fasting insulin resistance index (FIRI), and the quantitative insulin-sensitivity check index (QUICKI) were calculated. Results. No sequence variants were found except for the rs3856806. The frequency of the PPARG-His447His variant was $23.8 \%$ in the overall population group, with no difference by diabetes status $(P=0.215)$. The His447His allele T was associated with none of the markers of insulin resistance overall and by diabetes status. In models adjusted for 2-hour insulin, the $\mathrm{T}$ allele was associated with lower prevalent diabetes risk (odds ratio 0.56 (95\% CI 0.31-0.95)). Conclusion. Our study confirms the almost zero occurrences of known rare PPARG SNPs and has shown for the first time in an African population that one of the common SNPs, His447His, may be protective against type 2 diabetes.

\section{Introduction}

Peroxisome proliferator-activated receptor gamma (PPARG) is one of the three PPARs isotypes; the other two are PPAR $\alpha$ and PPAR $\beta / \delta$. The PPARG is mainly expressed in adipose tissue whilst PPAR $\alpha$ is expressed mostly in brown adipose tissue and liver, and $\operatorname{PPAR} \beta / \delta$, which is found in many tissues, is mostly expressed in gut, kidney, and heart $[1,2]$. Expression of PPARs occurs when heterodimers are formed with the retinoid $\mathrm{X}$ receptor (RXR) and binds to specific PPAR responsive elements of DNA to promote transcription. The PPAR: RXR complex is activated via ligand binding to PPARs resulting in the release of corepressors bound to the receptor and recruitment of coactivators to initiate transcription of target genes [3-5]. For example, antidiabetic drugs of the thiazolidinedione family are believed to target the transcription factor PPARG to improve insulin sensitivity in type 2 diabetes (T2D) and induce glucose transporter 4 mRNA expression in fat and muscle [6-8].

Naturally occurring PPARG polymorphisms have been described in several studies. The two common variants of the PPARG gene, Prol2Ala and His447His, have been associated with metabolic states of obesity, insulin resistance, type 2 diabetes, and metabolic syndrome [9]. The His447His polymorphism (also referred to as C161T, C1431T, or CAC478CAT, His449His) is a silent mutation at exon 6 
and is considered a better predictor of fasting insulin levels and insulin resistance than Prol2Ala [10]. In our previous analysis, the presence of PPARG Prol2 conferred a $64 \%$ higher risk of prevalent type 2 diabetes, but we failed to demonstrate an association with markers of insulin resistance [11]. In the present study, we therefore investigated the association between cardiometabolic traits, His447His, and other PPARG polymorphisms.

\section{Materials and Methods}

2.1. Baseline Evaluations. This investigation is based on the Bellville South cohort from Cape Town, South Africa, which has received study approval from the Research Ethics Committees of the University of Stellenbosch (HREC reference number N09/05/146) and Cape Peninsula University of Technology Faculty of Health and Wellness Sciences Ethics Committee (reference numbers CPUT/HW-REC 2008/002 and CPUT/HW-REC 2010). The study was conducted according to the code of ethics of the World Medical Association (Declaration of Helsinki). A detailed description of the research setting has been previously described $[12,13]$. Briefly, Bellville South is predominantly a mixed ancestry township located in the northern suburb of Cape Town in the Tygerberg subdistrict. The mixed ancestry, commonly referred to as coloured, is a South African population group with $32-43 \%$ Khoisan, 20-36\% Bantu-speaking African, 21-28\% European, and 9-11\% Asian ancestry [14]. All participants received a standardized interview and physical examination during which blood pressure was measured according to the World Health Organisation (WHO) guidelines [15] using a semiautomated digital blood pressure monitor (Rossmax PA, USA) on the right arm in a sitting position. Anthropometric measurements were performed three times and their average was used for analysis: weight $(\mathrm{kg})$, height $(\mathrm{cm})$, waist $(\mathrm{cm})$, and hip $(\mathrm{cm})$ circumferences. Participants with no history of doctor-diagnosed diabetes mellitus underwent a $75 \mathrm{~g}$ oral glucose tolerance test (OGTT) as recommended by the WHO [16]. Further, the following biochemical parameters were determined on the Cobas 6000 Clinical Chemistry instrument (Roche Diagnostics, Germany): fasting plasma glucose, insulin, creatinine, total cholesterol (TC), high density lipoprotein cholesterol (HDL-c), triglycerides (TG), Creactive protein (CRP), $\gamma$-glutamyltransferase (GGT), and glycated haemoglobin (HbAlc) certified by the National Glycohemoglobin Standardisation Programme (NGSP). Low density lipoprotein cholesterol (LDL-c) was calculated using Friedewald's formula [17].

2.2. SNP Genotyping. Genomic DNA was extracted from whole blood samples collected in an EDTA tube. Single nucleotide polymorphisms (SNPs) in the PPARG, Prol15Gln (rs1800571, G>T), Val290Met (rs72551362, G>A), Pheu388Leu (rs72551363, T>A), Arg397Cys (rs72551364, $\mathrm{C}>\mathrm{T}$ ), and His447His (rs3856806, C>T), were genotyped using high throughput real-time polymerase chain reaction (RT-PCR) in two independent laboratories on the ABI Prism 7900HT platform (Applied Biosystems, USA) and a BioRad Optica (BioRad, USA) using TaqMan genotyping assay
(Applied Biosystems, USA). Conventional polymerase chain reaction followed by direct DNA sequencing was performed for analytical validation of high throughput genotyping.

2.3. Definitions and Calculations. Body mass index (BMI) was calculated as weight per square meter $\left(\mathrm{kg} / \mathrm{m}^{2}\right)$ and waisthip-ratio (WHR) as waist/hip circumferences $(\mathrm{cm})$. Type 2 diabetes status was based on a history of doctor-diagnosis, a fasting plasma glucose $\geq 7.0 \mathrm{mmol} / \mathrm{L}$, and/or a 2 -hour postOGTT plasma glucose $\geq 11.1 \mathrm{mmol} / \mathrm{L}$. The homeostatic model assessment of insulin resistance (HOMA-IR) was calculated according to the formula HOMA-IR = fasting insulin concentration $(\mathrm{mIU} / \mathrm{L}) \times$ fasting plasma glucose $(\mathrm{mmol} / \mathrm{L}) / 22.5$, while functional $\beta$-cells (HOMA-B\%) were estimated using the formula $20 \times$ fasting insulin $(\mu \mathrm{IU} / \mathrm{mL}) /$ fasting glucose $(\mathrm{mmol} / \mathrm{mL})-3.5$. The fasting insulin resistance index (FIRI) was calculated with the formula (fasting insulin $(\mu \mathrm{U} / \mathrm{mL}) \times$ fasting glucose $(\mathrm{mM})) / 25$ and the quantitative insulinsensitivity check index (QUICKI) was calculated as $1 / \log$ fasting insulin $(\mu \mathrm{U} / \mathrm{mL}) \times \log$ (fasting glucose $(\mathrm{mg} / \mathrm{dL}))$. Glomerular filtration rate (GFR) was estimated by the 4variable modification of diet in renal disease (MDRD) equation $[18,19]$ applicable to standardised serum creatinine values.

2.4. Statistical Analysis. Of the 946 participants who took part in the survey, 941 consented for genetic studies. Among the latter, 121 were excluded for missing data on the genetic variables. Therefore, 820 had valid data for the current analyses. General characteristics of the study group are summarized as count and percentage for dichotomous traits, mean and standard deviation (SD), or median and 25th-75th percentiles for quantitative traits. Traits were log-transformed to approximate normality, where necessary, prior to analysis. SNPs were tested for departure from Hardy-Weinberg equilibrium (HWE) expectation via a chi-square goodness of fit test. Linear regression models were used for the analysis of quantitative traits and logistic regression models for dichotomous traits, always assuming additive models for the SNPs. Using linear and logistic models enabled us to adjust all analyses for known confounders as specified everywhere in the results. We investigated the additive allelic association of each SNP with each trait, overall and according to type 2 diabetes status, and tested for heterogeneity by adding the interaction term of type 2 diabetes and each SNP to a model that contained the main effects of type 2 diabetes and the relevant SNP. Results corresponding to $P$ values below 5\% are described as significant. We did not adjust for multiple testing. All analyses used the statistical package $\mathrm{R}$ (version 3.0.0 (2013-04-03), The R Foundation for Statistical Computing, Vienna, Austria).

\section{Results}

Clinical characteristics of participants overall and according to diabetes status are summarized in Table 1 indicating that 222 (27\%) participants had type 2 diabetes. As expected, the distribution of the level of insulin resistance/sensitivity indicators was significantly different between the two groups 
TABLE 1: General characteristics of the overall population and by diabetic status.

\begin{tabular}{|c|c|c|c|c|}
\hline Variable & No diabetes & Diabetes & $P$-value & Overall \\
\hline Number & 598 & 222 & & 820 \\
\hline Gender, male $n(\%)$ & $130(21.7)$ & $48(21.6)$ & 0.9474 & $178(21.7)$ \\
\hline Mean age, year (SD) & $51.0(15.1)$ & $58.9(13.4)$ & $<0.0001$ & $53.2(15.1)$ \\
\hline Mean systolic blood pressure, $\mathrm{mmHg}$ (SD) & $122(19)$ & $130(23)$ & $<0.0001$ & $124(21)$ \\
\hline Mean diastolic blood pressure, $\mathrm{mmHg}(\mathrm{SD})$ & $75(12)$ & $77(14)$ & 0.0506 & $76(13)$ \\
\hline Hypertension, $n(\%)$ & $314(52.5)$ & $133(59.9)$ & 0.05859 & $447(54.5)$ \\
\hline Mean body mass index, $\mathrm{kg} / \mathrm{m}^{2}(\mathrm{SD})$ & $29.2(7.0)$ & $31.8(7.1)$ & $<0.0001$ & $29.9(7.1)$ \\
\hline Mean waist circumference, cm (SD) & $95(15)$ & $102(14)$ & $<0.0001$ & $97(15)$ \\
\hline Mean hip circumference, cm (SD) & $109(14)$ & $112(15)$ & 0.014 & $109(14)$ \\
\hline Mean waist/hip ratio, (SD) & $0.87(0.10)$ & $0.91(0.10)$ & $<0.0001$ & $0.88(0.09)$ \\
\hline Mean HbAlc, \% (SD) & $5.7(0.4)$ & $7.8(2.1)$ & $<0.0001$ & $6.3(1.4)$ \\
\hline Mean fasting blood glucose, mmol/L (SD) & $5.1(0.7)$ & $9.8(4.5)$ & $<0.0001$ & $6.4(3.2)$ \\
\hline Mean $2 \mathrm{~h}$ glucose, mmol/L (SD) & $6.4(1.6)$ & $13.4(5.3)$ & $<0.0001$ & $7.5(3.6)$ \\
\hline Mean eGFR, mL/min (SD) & $76.2(21.2)$ & $72.0(25.2)$ & 0.029 & $75.0(22.4)$ \\
\hline Mean triglycerides, $\mathrm{mmol} / \mathrm{L}(\mathrm{SD})$ & $1.4(0.9)$ & $1.7(0.9)$ & $<0.0001$ & $1.5(0.9)$ \\
\hline Mean HDL cholesterol, mmol/L (SD) & $1.3(0.4)$ & $1.2(0.3)$ & 0.0002 & $1.3(0.4)$ \\
\hline Mean LDL cholesterol, mmol/L (SD) & $3.6(1.0)$ & $3.7(1.1)$ & 0.179 & $3.6(1.0)$ \\
\hline Mean total cholesterol, mmol/L (SD) & $5.5(1.2)$ & $5.7(1.3)$ & 0.068 & $5.6(1.2)$ \\
\hline Median GGT (25th-75th percentiles) & $26[17-39]$ & $32[23-49]$ & $<0.0001$ & $27[19-42]$ \\
\hline Median CRP (25th-75th percentiles) & $3.3[0.9-8.3]$ & $5.4[2.2-10.9]$ & $<0.0001$ & $4.0[1.2-9.4]$ \\
\hline Median insulin mmol/L (25th-75th percentiles) & $7.2[3.4-12.9]$ & $10.2[4.4-17.6]$ & 0.0001 & $7.7[3.5-14.1]$ \\
\hline Median $2 \mathrm{~h}$ insulin mmol/L (25th-75th percentiles) & $36.0[19.3-65.7]$ & $53.3[22.1-117.0]$ & 0.0015 & $37.3[19.5-72.7]$ \\
\hline Median glucose/insulin (25th-75th percentiles) & $0.71[0.40-1.45]$ & $0.82[0.48-2.05]$ & 0.0304 & $0.72[0.41-1.58]$ \\
\hline Median HOMA-IR (25th-75th percentiles) & $1.63[0.69-3.00]$ & $3.67[1.71-7.29]$ & $<0.0001$ & $1.94[0.86-3.82]$ \\
\hline Median HOMA-B\% (25th-75th percentiles) & $92.8[43.5-165.1]$ & $42.1[13.6-83.4]$ & $<0.0001$ & $74.2[32.2-149.2]$ \\
\hline Median QUICKI (25th-75th percentiles) & $0.15[0.14-0.18]$ & $0.14[0.12-0.15]$ & $<0.0001$ & $0.15[0.14-0.17]$ \\
\hline Median FIRI (25th-75th percentiles) & $1.46[0.62-2.70]$ & $3.31[1.54-6.56]$ & $<0.0001$ & $1.74[0.77-3.44]$ \\
\hline Median 1/HOMA-IR (25th-75th percentiles) & $0.61[0.33-1.44]$ & $0.27[0.14-0.58]$ & $<0.0001$ & $0.52[0.26-1.16]$ \\
\hline
\end{tabular}

CRP: C-reactive protein; eGFR: estimated glomerular filtration rate; FIRI: fasting insulin-resistance index; GGT: $\gamma$-glutamyltransferase; HbAlc: glycated haemoglobin; HDL: high density lipoproteins; HOMA-B\%: functional $\beta$-cells; HOMA-IR: homeostatic model assessment of insulin resistance; LDL: low density lipoproteins; QUICKI: the quantitative insulin-sensitivity check index; SD: standard deviation.

all $P<0.0001$, except for glucose/insulin ratio $(P=0.0304)$. Furthermore, compared with nondiabetic participants, those with diabetes were significantly older (58.9 versus 51.0 years, $P<0.0001)$ and had higher levels of adipometric variables (all $P \leq 0.014)$, systolic blood pressure $(P<0.0001)$, triglycerides $(P<0.0001)$, GGT, and CRP (both $P<0.0001)$, whilst eGFR $(P=0.029)$ and HDL cholesterol $(P=0.0002)$ were significantly lower.

No mutations were found for the following SNPs of PPARG: Prol15Gln, Val290Met, Pheu388Leu, and Arg397Cys. The PPARG, His447His, variant was in $\mathrm{HWE}$ $(P>0.05)$ and its genotype and allele distribution overall and by diabetes status are summarized in Table 2 . The frequency of the PPARG (rs3856806), C/T genotype, was $23.8 \%$ in the overall population group and the genotype distributions did not differ significantly between the nondiabetic and diabetic groups. Overall, the T allele frequency was 14\%; however, although not significant $(P=0.128)$, the $\mathrm{T}$ allele did occur more in the nondiabetic (14.8\%) than in the diabetic $(11.7 \%)$ participants.

In generalized linear regression analyses adjusted for age, sex and diabetes (Table 3), PPARG His447His allele T was associated with none of the markers of insulin resistance overall and by diabetes status. There was a borderline statistical interaction in the effect by diabetes status for the association with fasting glucose (interaction $P=0.092$ ), HOMA-IR and FIRI indices (both $P=0.076$ ). Furthermore, the effects always appeared to be sizable and negative (although nonsignificant) among the diabetic and almost null in nondiabetic participants.

In the logistic regression models (Table 4) PPARG allele $\mathrm{T}$ was associated with odds ratio of 0.76 (95\% confidence interval 0.55-1.05) for prevalent diabetes. The effect estimates broadly remained within the same range after adjustment for 
TABLE 2: Genotype distributions, minor allele frequencies, and unadjusted $P$-values for comparing genotype distribution according to diabetes status and additive allelic effects between diabetes groups.

\begin{tabular}{lcccc}
\hline & No diabetes & Diabetes & Overall \\
\hline$N$ & $\mathbf{5 9 8}$ & $\mathbf{2 2 2}$ & & $\mathbf{8 2 0}$ \\
PPARG (rs3856806) & & & & \\
$\mathrm{C} / \mathrm{C}, n(\%)$ & $436(72.9)$ & $172(77.5)$ & 0.215 & $608(74.1)$ \\
$\mathrm{C} / \mathrm{T}, n(\%)$ & $147(24.5)$ & $2(0.9)$ & $195(23.8)$ \\
$\mathrm{T} / \mathrm{T}, n(\%)$ & $15(2.5)$ & $52(11.7)$ & 0.128 & $17(2.1)$ \\
$\mathrm{T}, n(\%)$ & $177(14.8)$ & 0.747 & $229(14.0)$ \\
HWE $(P$-value $)$ & 0.517 & 0.771 \\
\hline
\end{tabular}

HWE: Hardy-Weinberg equilibrium (HWE $P$-values are from exact tests); PPARG: peroxisome proliferator-activated receptor gamma.

age and sex, with or without further adjustment for various indices of insulin resistance/sensitivity. However, in model containing sex, age, and 2-hour insulin, PPARG allele T was significantly associated with a lower prevalent diabetes risk with an odds ratio of 0.56 (95\% CI: 0.31-0.95).

\section{Discussion}

The present study reports five PPARG SNPs, rs1800571, rs72551362, rs72551363, rs72551364, and rs3856806. Only His447His (rs3856806) was found to be polymorphic and demonstrated an association with diabetes risk. The $\mathrm{T}$ allele frequencies were about $14 \%$ and, in an additive genetic model, we observed that the presence of the $\mathrm{T}$ allele significantly reduced the risk of diabetes by $44 \%$. Furthermore, the $\mathrm{T}$ allele was associated with reduced fasting blood glucose levels and HOMA-IR and FIRI indices. However these associations were borderline and did not reach statistical significance.

The nuclear transcription receptor, PPARG, acts as a regulator of adipocyte differentiation, pancreatic beta cell function, and lipid and glucose metabolism [20-22]. Despite its biological plausibility, previously reported association studies with obesity [23-25], insulin resistance [10, 25], type 2 diabetes [11, 26], and metabolic syndrome [27] are conflicting. For instance, some studies have reported that carriers of the $\mathrm{T}$ allele of His447His (rs3856806) have increased obesity risk [23], poor lipid profile [28-30], and risk of metabolic syndrome [27] and coronary heart diseases (CHD) [9]. On the other hand, others have failed to demonstrate an association between PPARG SNPs including C161T with CHD susceptibility [31], whilst some have shown increased insulin sensitivity $[10,26]$, decreased CHD, body mass index, and diabetes risk $[25,26,29,32]$ in subjects harbouring the $\mathrm{T}$ allele. In our study, presence of the $\mathrm{T}$ allele was associated with reducing the risk of prevalent diabetes and levels of insulin resistance indices. Aspects that may contribute to the inconsistencies in these studies include variations in ethnic distribution of PPARG polymorphisms, the statistical power of the studies, environmental-gene and gene-gene factors, and different levels of adjustment for potential confounding factors across studies. For example, in our study, the T allele frequency of the His447His variant (14\%) was similar to that reported in the Australian Caucasians, 16.3\% [2], and the
Tunisians, $18.3 \%$ [27], whilst in the Chinese a frequency of $29.2 \%$ has been reported [33]. Furthermore, two recent studies have shown that gene-gene interaction analysis is superior to single PPARG polymorphisms for the quantification of effects with cardiometabolic traits [33, 34]. For example, Luo et al. [33] investigated the association of 10 PPARG SNPs with obesity and found that only two SNPs, rs2016520 and rs10865170, were associated with lower obesity risk. However, in generalized multifactor dimensionality reduction analysis to assess the effect of interaction among the 10 SNPs, an additional SNP, rs9794, was identified and showed a potential gene-gene interaction with rs2016520 and rs10865170 [33].

We also genotyped some of the PPARG SNPs, rs1800571, rs72551362, rs72551363, and rs72551364, but no genetic variations were observed. The rs1800571, Pro115Gln, gain-offunction mutation has only been found in five German morbid obese subjects since its initial identification by Ristow et al. [35], where three of the four obese subjects with the genetic variant also had type 2 diabetes. In another German population study, another carrier of the mutant with severe insulin resistance was identified [36]. However, other studies involving German, Danish, and American populations failed to find this mutation [37-40]. Similarly, there has not been more than one individual in which either rs72551362, rs72551363, or rs72551364 has been found [4143]. The rare nature of these mutations suggests that standard population-based type studies are likely not the suitable design to investigate them, considering the requirements for very large sample size. Rather, targeting specific segments of the population such as people with morbid obesity for screening may increase the likelihood of uncovering some with the mutation. It is also possible that mutations other than those reported so far could be present in other populations, indicating the need for genome-wide scanning studies in different setting to capture additional mutations.

Our study has some limitations and these include the investigation of only five SNPs and small sample size. However, the participants in this study were well characterised and we used both fasting and oral glucose tolerance test derived indices for the assessment of type 2 diabetes and insulin resistance. In conclusion, our study confirmed the almost zero occurrences of known rare PPARG SNPs and has shown that one of the common SNPs, His447His, may be protective 


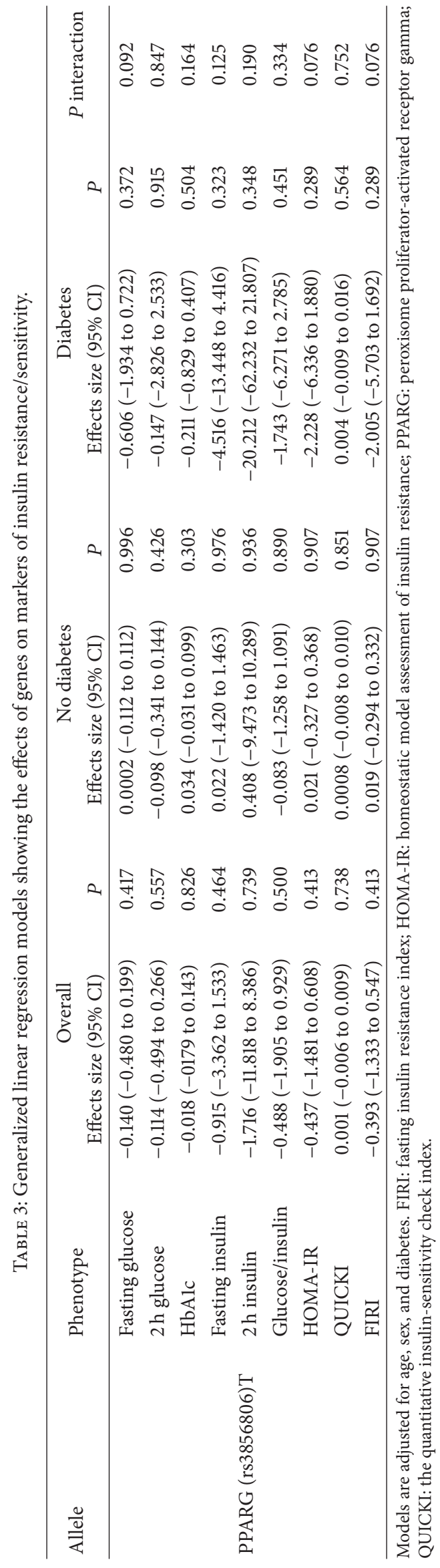


TABLE 4: Odds ratio and 95\% confidence intervals from logistic regression for the prediction of diabetes.

\begin{tabular}{llll}
\hline Allele & Covariates & OR (95\% CI) & $P$ \\
\hline & None & $0.76(0.55$ to 1.06$)$ & 0.112 \\
PPARG (rs3856806)T & sex, age & $0.74(0.53$ to 1.03$)$ & 0.082 \\
& sex, age, insulin & $0.75(0.53$ to 1.05$)$ & 0.098 \\
& sex, age, 2 h insulin & $0.56(0.31$ to 0.95$)$ & 0.042 \\
& sex, age, HOMA-IR & $0.77(0.53$ to 1.10$)$ & 0.157 \\
& sex, age, QUICKI & $0.75(0.53$ to 1.04$)$ & 0.094 \\
& sex, age, FIRI & $0.77(0.53$ to 1.10$)$ & 0.157 \\
\hline
\end{tabular}

FIRI: fasting insulin resistance index; HOMA-IR: homeostatic model assessment of insulin resistance; PPARG: peroxisome proliferator-activated receptor; QUICKI: the quantitative insulin-sensitivity check index.

against type 2 diabetes. Future larger studies with more SNPs involving populations from Africa need further exploration.

\section{Conflict of Interests}

The authors declare that there is no conflict of interests regarding the publication of this paper.

\section{Authors' Contribution}

Z. Vergotine contributed to the acquisition of data, preparation of the first draft, and approval of the final draft. Y. Y. Yako contributed to the acquisition of data and approval of final the draft. A. P. Kengne contributed to the analysis and interpretation of data, revision for important intellectual content, and approval of the final draft. R. T. Erasmus contributed to the conception and design, revision for important intellectual content, and approval of the final draft. T. E. Matsha contributed to the conception and design, acquisition and interpretation of data, preparation of the first draft, and approval of the final draft.

\section{Funding}

Funding was received from South African Medical Research Council, Cape Peninsula University of Technology, South Africa, and Harry Crossly Foundation, University of Stellenbosch, South Africa.

\section{Acknowledgment}

The authors gratefully acknowledge the Bellville South Community of Cape Town, South Africa, for participating in the study.

\section{References}

[1] B. Desvergene and W. Wahli, "Peroxisome proliferatoractivated receptors: nuclear control of metabolism," Endocrine Reviews, vol. 20, pp. 649-688, 1999.

[2] X. L. Wang, J. Oosterhof, and N. Duarte, "Peroxisome proliferator-activated receptor $\gamma \mathrm{Cl61} \rightarrow \mathrm{T}$ polymorphism and coronary artery disease," Cardiovascular Research, vol. 44, no. 3, pp. 588-594, 1999.
[3] R. Mukherjee, P. A. Hoener, L. Jow et al., "A selective peroxisome proliferator-activated receptor- $\gamma$ (PPAR $\gamma$ ) modulator blocks adipocyte differentiation but stimulates glucose uptake in 3T3L1 adipocytes," Molecular Endocrinology, vol. 14, no. 9, pp. 14251433, 2000.

[4] S. S. Deeb, L. Fajas, M. Nemoto et al., "A Pro12Ala substitution in PPAR $\gamma 2$ associated with decreased receptor activity, lower body mass index and improved insulin sensitivity," Nature Genetics, vol. 20, no. 3, pp. 284-287, 1998.

[5] G. Pascual, A. L. Fong, S. Ogawa et al., "A SUMOylationdependent pathway mediates transrepression of inflammatory response genes by PPAR- $\gamma$," Nature, vol. 437, no. 7059, pp. 759763, 2005.

[6] M. Armoni, N. Kritz, C. Harel et al., "Peroxisome proliferatoractivated receptor- $\gamma$ represses GLUT4 promoter activity in primary adipocytes, and rosiglitazone alleviates this effect," Journal of Biological Chemistry, vol. 278, no. 33, pp. 3061430623, 2003.

[7] B. Cariou, B. Charbonnel, and B. Staels, "Thiazolidinediones and PPAR $\gamma$ agonists: time for a reassessment," Trends in Endocrinology \& Metabolism, vol. 23, no. 5, pp. 205-215, 2012.

[8] H. Yau, K. Rivera, R. Lomonaco, and K. Cusi, "The future of thiazolidinedione therapy in the management of type 2 diabetes mellitus," Current Diabetes Reports, vol. 13, no. 3, pp. 329-341, 2013.

[9] S. Ding, L. Liu, Q. Zhuge et al., "The meta-analysis of the association of PPARG P12A, C161T polymorphism and coronary heart disease," Wiener Klinische Wochenschrift, vol. 124, no. 19-20, pp. 671-677, 2012.

[10] S. P. Moffett, E. Feingold, M. M. Barmada et al., "The C161 $\rightarrow$ $\mathrm{T}$ polymorphism in peroxisome proliferator-activated receptor gamma, but not P12A, is associated with insulin resistance in Hispanic and non-Hispanic white women: evidence for another functional variant in peroxisome proliferator-activated receptor gamma," Metabolism: Clinical and Experimental, vol. 54, no. 11, pp. 1552-1556, 2005.

[11] Z. Vergotine, Y. Y. Yako, A. P. Kengne et al., "Proliferatoractivated receptor gamma Prol2Ala interacts with the insulin receptor substrate 1 Gly972Arg and increase the risk of insulin resistance and diabetes in the mixed ancestry population from South Africa," BMC Genetics, vol. 15, p. 10, 2014.

[12] A. E. Zemlin, T. E. Matsha, M. S. Hassan, and R. T. Erasmus, "HbAlc of $6.5 \%$ to diagnose diabetes mellitus-does it work for us? The bellville South Africa study," PLoS ONE, vol. 6, no. 8, Article ID e22558, 2011. 
[13] T. E. Matsha, D. J. Soita, M. S. Hassan et al., "Three-year's changes in glucose tolerance status in the Bellville South cohort: rates and phenotypes associated with progression," Diabetes Research and Clinical Practice, vol. 99, no. 2, pp. 223-230, 2013.

[14] E. de Wit, W. Delport, C. E. Rugamika et al., "Genomewide analysis of the structure of the South African Coloured Population in the Western Cape," Human Genetics, vol. 128, no. 2, pp. 145-153, 2010.

[15] J. Chalmers, S. MacMahon, G. Mancia et al., "World Health Organization-international society of hypertension guidelines for the management of hypertension. Guidelines subcommittee of the World Health Organization," Clinical and Experimental Hypertension, vol. 21, pp. 1009-1060, 1999.

[16] K. G. Alberti and P. Z. Zimmet, "Definition, diagnosis and classification of diabetes mellitus and its complications. Part 1: diagnosis and classification of diabetes mellitus provisional report of a WHO consultation," Diabetic Medicine, vol. 15, pp. 539-553, 1998.

[17] W. T. Friedewald, R. I. Levy, and D. S. Fredrickson, "Estimation of the concentration of low-density lipoprotein cholesterol in plasma, without use of the preparative ultracentrifuge," Clinical Chemistry, vol. 18, no. 6, pp. 499-502, 1972.

[18] A. S. Levey, J. P. Bosch, J. B. Lewis, T. Greene, N. Rogers, and D. Roth, "A more accurate method to estimate glomerular filtration rate from serum creatinine: a new prediction equation," Annals of Internal Medicine, vol. 130, no. 6, pp. 461-470, 1999.

[19] A. S. Levey, J. Coresh, and T. Greene, "Chronic Kidney Disease Epidemiology Collaboration. Using standardized serum creatinine values in the modification of diet in renal disease study equation for estimating glomerular filtration rate," Annals of Internal Medicine, vol. 145, pp. 247-254, 2006.

[20] B. M. Spiegelman, "Peroxisome proliferator-activated receptor gamma: a key regulator of adipogenesis and systemic insulin sensitivity," European Journal of Medical Research, vol. 2, no. 11, pp. 457-464, 1997.

[21] E. D. Rosen, R. N. Kulkarni, P. Sarraf et al., “Targeted elimination of peroxisome proliferator-activated receptor $\gamma$ in $\beta$ cells leads to abnormalities in islet mass without compromising glucose homeostasis," Molecular and Cellular Biology, vol. 23, no. 20, pp. 7222-7229, 2003.

[22] A. L. Hevener, W. He, Y. Barak et al., "Muscle-specific Pparg deletion causes insulin resistance," Nature Medicine, vol. 9, no. 12, pp. 1491-1497, 2003.

[23] R. Valve, K. Sivenius, R. Miettinen et al., "Two polymorphisms in the peroxisome proliferator-activated receptor-gamma gene are associated with severe overweight among obese women," Journal of Clinical Endocrinology and Metabolism, vol. 84, no. 10, pp. 3708-3712, 1999.

[24] A. Meirhaeghe, L. Fajas, N. Helbecque et al., "A genetic polymorphism of the peroxisome proliferator-activated receptor $\gamma$ gene influences plasma leptin levels in obese humans," Human Molecular Genetics, vol. 7, no. 3, pp. 435-440, 1998.

[25] L. Dongxia, H. Qi, L. Lisong, and G. Jincheng, "Association of peroxisome proliferator-activated receptor $\gamma$ gene Pro12Ala and C161T polymorphisms with metabolic syndrome," Circulation Journal, vol. 72, no. 4, pp. 551-557, 2008.

[26] E. S. Tai, D. Corella, M. Deurenberg-Yap et al., "Differential effects of the C1431T and Pro12Ala PPAR $\gamma$ gene variants on plasma lipids and diabetes risk in an Asian population," Journal of Lipid Research, vol. 45, no. 4, pp. 674-685, 2004.

[27] S. M. Youssef, N. Mohamed, S. Afef et al., "Combined effects of the C161T and Pro12Ala PPAR 22 gene variants with insulin resistance on metabolic syndrome: a case-control study of a central Tunisian population," Journal of Molecular Neuroscience, vol. 52, pp. 487-492, 2014.

[28] S. J. Gu, M. M. Liu, Z. R. Guo et al., "Gene-gene interactions among PPAR $\alpha / \delta / \gamma$ polymorphisms for hypertriglyceridemia in Chinese Han population," Gene, vol. 25, pp. 272-276, 2013.

[29] H. Yilmaz-Aydogan, O. Kurnaz, O. Kucukhuseyin et al., "Different effects of PPARA, PPARG and ApoE SNPs on serum lipids in patients with coronary heart disease based on the presence of diabetes," Gene, vol. 523, no. 1, pp. 20-26, 2013.

[30] E. J. Rhee, K. W. Oh, W. Y. Lee et al., "Effects of two common polymorphisms of peroxisome proliferator-activated receptorgamma gene on metabolic syndrome," Archives of Medical Research, vol. 37, pp. 86-94, 2006.

[31] W. Xu, J. Xu, B. Sun et al., "The effect of PPARG gene polymorphisms on the risk of coronary heart disease: a meta-analysis," Molecular Biology Reports, vol. 40, no. 2, pp. 875-884, 2013.

[32] Y. Liu, Z. Yuan, J. Zhang et al., "PPAR $\gamma$ gene C161T substitution is associated with reduced risk of coronary artery disease and decreased proinflammatory cytokine expression," The American Heart Journal, vol. 154, no. 4, pp. 718-724, 2007.

[33] W. Luo, Z. Guo, M. Wu et al., "Association of peroxisome proliferator-activated receptor $\alpha / \delta / \gamma$ with obesity, and genegene interaction, in the Chinese Han population," Journal of Epidemiology, vol. 23, pp. 187-194, 2013.

[34] K. H. Chan, T. Niu, Y. Ma et al., "Common genetic variants in peroxisome proliferator-activated receptor- $\gamma$ (PPARG) and type 2 diabetes risk among Women's Health Initiative postmenopausal women," The Journal of Clinical Endocrinology and Metabolism, vol. 98, pp. E600-E604, 2013.

[35] M. Ristow, D. Müller-Wieland, A. Pfeiffer, W. Krone, and C. R. Kahn, "Obesity associated with a mutation in a genetic regulator of adipocyte differentiation," The New England Journal of Medicine, vol. 339, no. 14, pp. 953-959, 1998.

[36] M. Blüher and R. Paschke, "Analysis of the relationship between PPAR- $\gamma 2$ gene variants and severe insulin resistance in obese patients with impaired glucose tolerance," Experimental and Clinical Endocrinology \& Diabetes, vol. 111, no. 2, pp. 85-90, 2003.

[37] A. Hamann, H. Münzberg, P. Buttron et al., "Missense variants in the human peroxisome proliferator-activated receptorgamma2 gene in lean and obese subjects," European Journal of Endocrinology, vol. 141, pp. 90-92, 1999.

[38] D. Evans, W. A. Mann, J. De Heer et al., "Variation in the gene for human peroxisome proliferator activated receptor $\gamma$ $(\operatorname{PPAR} \gamma)$ does not play a major role in the development of morbid obesity," International Journal of Obesity, vol. 24, no. 5, pp. 647-651, 2000.

[39] J. Ek, S. A. Urhammer, T. I. A. Sørensen, T. Andersen, J. Auwerx, and O. Pedersen, "Homozygosity of the Prol2Ala variant of the peroxisome proliferation-activated receptor- $\gamma 2$ (PPAR- $\gamma 2)$ : divergent modulating effects on body mass index in obese and lean Caucasian men," Diabetologia, vol. 42, no. 7, pp. 892-895, 1999.

[40] A. R. Shuldiner, W. Nguyen, W. H. L. Kao et al., "Prol15Gln peroxisome proliferator-activated receptor- $\gamma$ and obesity," Diabetes Care, vol. 23, no. 1, pp. 126-127, 2000.

[41] R. A. Hegele, H. Cao, S. B. Harris, B. Zinman, A. J. G. Hanley, and C. M. Anderson, "Peroxisome proliferator-activated receptor- $\gamma 2$ P12A and type 2 diabetes in Canadian Oji-Cree," Journal of Clinical Endocrinology and Metabolism, vol. 85, no. 5, pp. 2014-2019, 2000. 
[42] I. Barroso, M. Gurnell, V. E. F. Crowley et al., "Dominant negative mutations in human $\operatorname{PPAR} \gamma$ associated with severe insulin resistance, diabetes mellitus and hypertension," Nature, vol. 402, no. 6764, pp. 880-883, 1999.

[43] A. K. Agarwal and A. Garg, "A novel heterozygous mutation in peroxisome proliferator-activated receptor- $\gamma$ gene in a patient with familial partial lipodystrophy," The Journal of Clinical Endocrinology \& Metabolism, vol. 87, no. 1, pp. 408-411, 2002. 


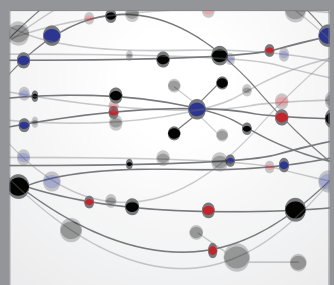

The Scientific World Journal
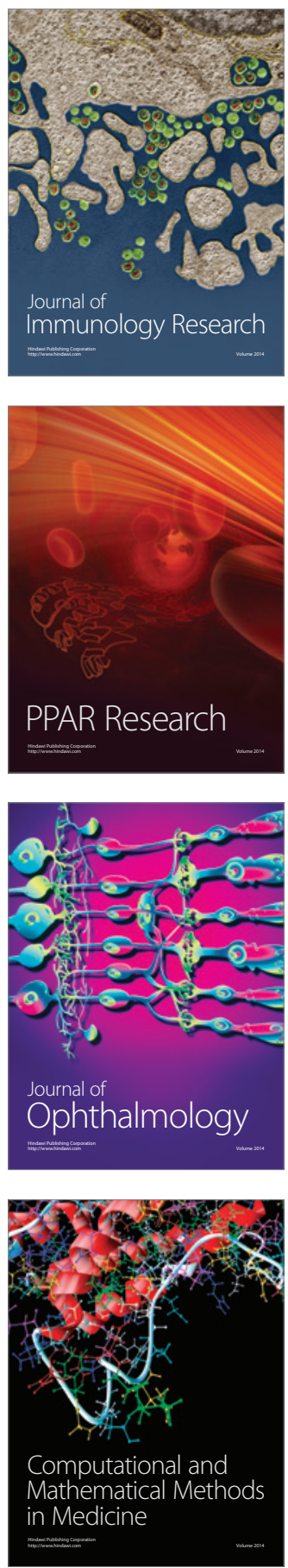

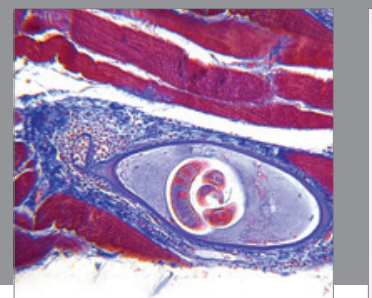

Gastroenterology

Research and Practice
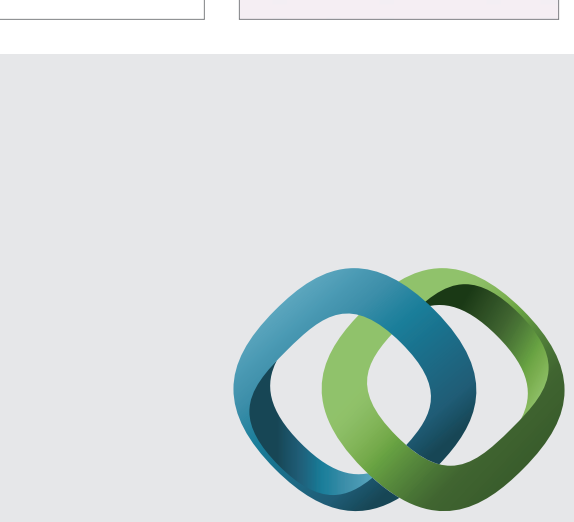

\section{Hindawi}

Submit your manuscripts at

http://www.hindawi.com
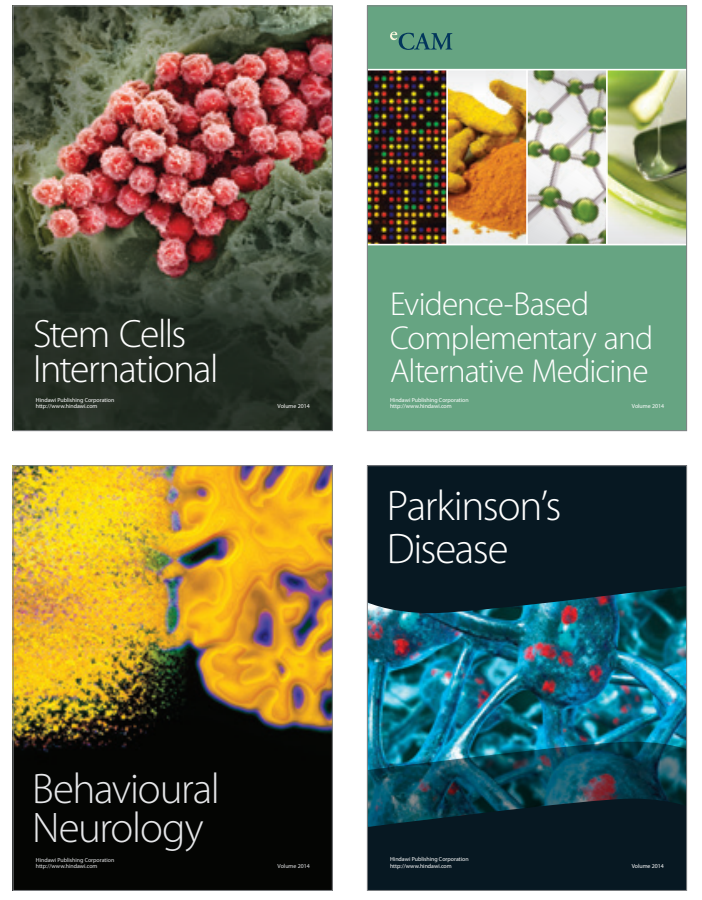
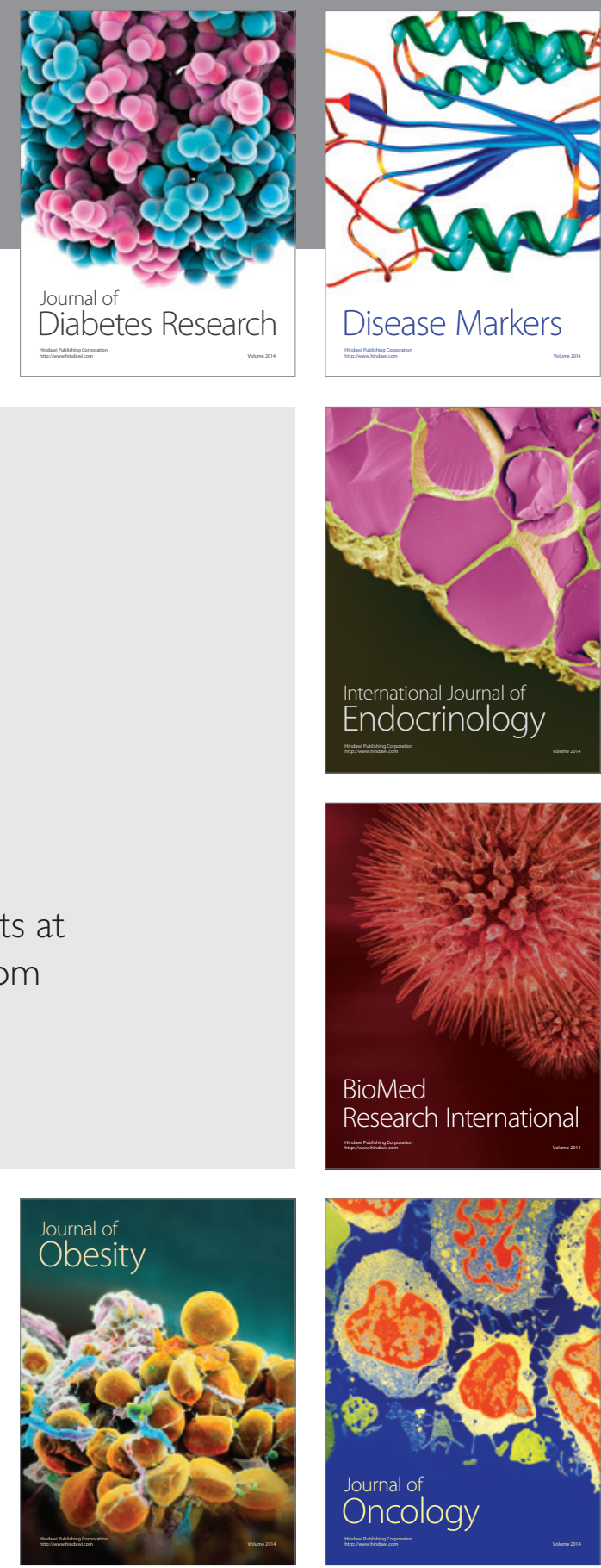

Disease Markers
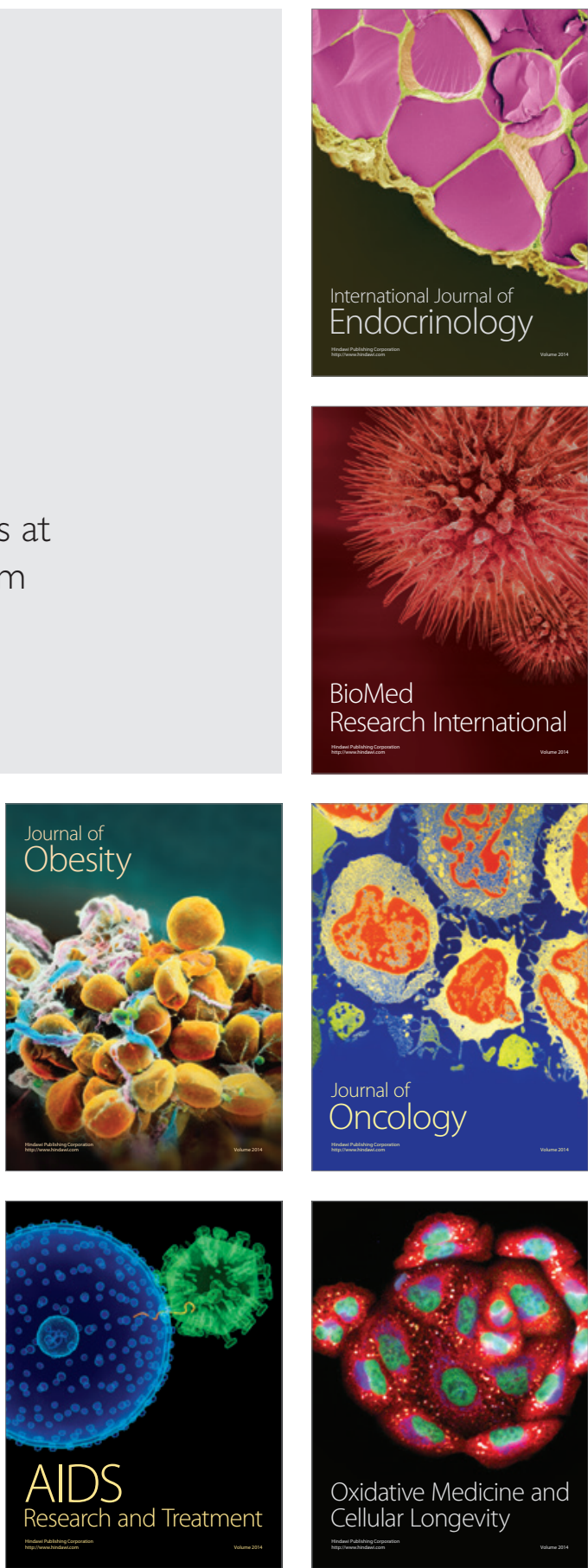